Artigo

\title{
APRENDER matemáticaS: UM ENCONTRO COM SIGNOS
}

\author{
Learning mathematics: a meeting with signs
}

Aprender matemáticas: un encuentro con signos

\author{
Michela Tuchapesk da Silva ${ }^{1}$ \\ (D) [0000-0002-6298-1137] \\ Carolina Tamayo ${ }^{2}$ \\ [0000-0002-8478-7845]
}

\section{Resumo}

Este texto tem por objetivo mobilizar a teoria do signo de Gilles Deleuze, junto a algumas ações práticas e teóricas realizadas com os(as) alunos(as) das disciplinas de estágio supervisionado de duas Licenciaturas em Matemática. Por meio de uma escrita (im)pertinente, descompactada e que dança num ritmo descontraído com a vida que acontece na escola, buscamos tensionar, desnaturalizar e provocar outras formas de compreender o aprender matemáticaS, vinculado ao pensar como ação e não como resultado da recognição. Encontramos na proposta deleuziana, tecida com as (im)pertinências produzidas pelos professores em formação inicial, a possibilidade de pensar um aprender com signos, um aprender pelos afectos, em que se manifesta um pensar que nasce e renasce para liberar a afirmação da diferença.

Palavras-chave: Filosofia da diferença. Signos. Educação Matemática.

\begin{abstract}
This text aims to mobilize the theory of the sign of Gilles Deleuze, along with some practical and theoretical actions carried out with the students of the supervised academic training disciplines of two degrees in Mathematics. Through (im)pertinent, uncompressed writing that dances at a carefree pace with the life that happens at school, we seek to tension, denaturalize and provoke other ways of understanding mathematics learning, linked to thinking as an action and not as a result of recognition. We find in the Deleuzian ideas, stitched with the (im)pertinences produced by teachers in initial formation, the possibility of thinking about learning with signs, learning through affections, in which a thinking that is born and reborn is manifested to release the affirmation of difference.
\end{abstract}

Keywords: Philosophy of difference. Signs. Mathematics Education.

\section{Resumen}

Este texto tiene como objetivo movilizar la teoría del signo de Gilles Deleuze, junto con algunas acciones prácticas y teóricas llevadas a cabo con los estudiantes de dos Licenciaturas en Matemáticas en la disciplina de práctica profesional. Por medio de una escritura (im)pertinente, descompactada y que baila con un ritmo descontraído con la vida que sucede en la escuela, buscamos tensionar, desnaturalizar y provocar otras formas de comprender el aprender matemáticaS, vinculado al pensar como acción y no como resultado de la recognición. Encontramos en la propuesta deleuziana, tejida junto a las (im)pertinencias producidas por los profesores en formación inicial, una posibilidad de pensar un aprender con signos, un aprender por afectos, en el que se manifiesta un pensar que nace y renace para liberar la afirmación de la diferencia.

\footnotetext{
${ }^{1}$ michelat@usp.br, Doutora em Educação Matemática, Professora da Faculdade de Educação da Universidade de São Paulo, São Paulo/SP/Brasil.

${ }^{2}$ carolinatamayo36@ufmg.br, Doutora em Educação, Professora da Faculdade de Educação da Universidade Federal de Minas Gerais, Belo Horizonte/MG/Brasil.
} 
Keywords: Filosofía de la diferencia. Signos. Educación Matemática.

\title{
$1(\mathrm{Im})$ pertinências
}

Este artigo busca movimentar algumas ações práticas e teóricas realizadas junto aos alunos das disciplinas de Estágio Supervisionado de duas Licenciaturas em Matemática, que tem provocado e provocam caminhos de resistências diante de práticas prescritivas que orientam a vida na escola e a vida na sala de aula de Matemática. Junto à teoria dos signos na perspectiva de Deleuze $(1988 ; 2003$; 2006) e Deleuze \& Parnet (1998) percebemos possibilidades de linhas de fuga, de transgressões, que problematizam a noção de aprendizagem de Matemática ${ }^{3}$ como recognição ${ }^{4}$ no contexto da Educação Matemática.

Buscando uma perspectiva rizomática, ao longo do texto, apresentamos escritas dos(as) alunos(as) em formação, produzidas nas disciplinas de Estágio Supervisionado, destacadas nos box - demarcado pelos símbolos $¥ ¥$ - intitulados '(im)pertinências' ${ }^{5}$. Estas (im)pertinências surgiram a partir das observações dos(as) alunos(as) enquanto estagiários(as) na sala de aula de Matemática de algumas escolas públicas e particulares do Ensino Básico do Estado de São Paulo. Tais produções discursivas foram realizadas sob a orientação das autoras deste artigo, em qualidade de professoras, procurando praticar a prática da escritura de forma errante, fazendo-a se desbordar para além do perceptível da vida de um(a) estagiário(a) na escola.

\begin{abstract}
Uma escrita para nada, escrita suja, carnal e fecunda, vizinha do estrangeiro, da falta de representação, pois atravessada por devires, não consegue tomar distância de uma política, de um modo de estar no mundo, de uma maneira de ser que inventa seus próprios meios de respirar. (COSTA; ROSA, 2017, p. 1).
\end{abstract}

A intencionalidade dessa escrita buscou contribuir para o desenvolvimento de um exercício prático e teórico das relações e afetações escolares. Em algumas (im)pertinências, os(as) estagiários(as), brincando com as palavras e com as imagens, operando com aquilo que sai do padrão, que abre margem para o aparecimento do acontecimento, produziram poesias, pinturas, pensamentos outros que envolvem a escola e, particularmente, a sala de aula de Matemática.

Resistindo a linguagem convencional das escritas tradicionais produzidas nos Estágios Supervisionados, por meio de um estilo que possibilita o ensinar, o aprender, o pensar, o sentir, dançarem a ritmos inimagináveis, os professores de Matemática em formação inicial produziram na escola, múltiplas sonoridades. Dispostos a olhares e sentidos e escutas outras, possibilitamos novas entradas e saídas, linhas de fuga, que desestabilizam os padrões, o 'normal'.

\footnotetext{
${ }^{3} \mathrm{O}$ uso da palavra Matemática com " $M$ " maiúsculo se refere a disciplina acadêmica nomeada pela cultura ocidental. Na perspectiva de Clareto (2013), inspirada na leitura de Gilles Deleuze é a chamada matemática maior ou uma matemática régia. Os conteúdos desta matemática são apresentados sequencialmente como formas prontas. As definições buscam pela substância e pela essência. Esta Matemática é acompanhada por avaliações pontuais e sistemáticas.

${ }^{4}$ Deleuze (2006).

${ }^{5}$ Estas escritas são aqui publicadas seguindo o Termo de Livre Consentimento para Pesquisa assinado pelos(as) alunos(as).
} 
Cabe a pergunta: Por que duas professoras de Matemática se aproximam da teoria dos signos de Gilles Deleuze para pensar 'o aprender' junto aos professores em formação inicial? Durante nossos percursos investigativos, temos procurado caminhos outros para pensar a escola e, nesse deslocamento temos encontrado na filosofia autores com propostas transgressoras que abrem margem para outras formas de entender o conhecer, vinculado ao pensar como ação e não como recognição. Ideias e conceitos que vão além das usuais perspectivas que, em Educação (Matemática), entendem o processo de conhecer como a organização do 'mundo sensível' através do 'mundo das ideias' (PLATÃO, 427? - 347? a.c), visto que os sujeitos simplesmente experimentam, eles não são conduzidos às experimentações, e os acontecimentos irrompem, não retratam o desígnio de uma vontade (UBERTI e BELLO, 2013).

\section{$¥ ¥$}

\section{O Pensamento do "aluno com fuso"}

Um balão. Alô bala, bala, só 10 a bala. Ai amor, não aperta minha bunda. Galerinha, vamo mexer a raba? Miga, olha que professor gato! Hey, meninas, quem vai o baile hoje? Menino, que horas são? QUAL A PROXXIMA AULA? Quem fez o trabalho de química? Gente, e a redação de português? Uia, fiz Booyah! Vem, vamo jogar! Olha Whats porfa? AE SAI DA FKENTE. Gente, silêncio! "PERDI"! Chocolate, olha o chocolate! Ai, eu to gorda.. Olha, meu but! Vamo jogar um fut? Se liga no corte! Ae achorro, me passa a lição? Dupla é de Três? Pode fazer uma dupla de duplas? Tem da boa? To ficando estressado...Em casa vou jogar um monte. Meu pai não quer me dar a grana pra eu sair... MIGA, vou dar um monte no final de semana!! Ei, Ei, Ei, Ei, Ei, Ei, Ei, Ei, $E_{i}, E_{i}, E_{i}, E_{i}, E_{i}, E_{i}, E_{i}, E_{i}, E_{i}, E_{i}, E_{i}, E_{i}, E_{i}, E_{i}$, $E_{i}, E_{i}, E_{i}, E_{i}, E_{i}, E_{i}, E_{i}$, vamo beber? INTERVALO INTERVALO IINNTTEERRVVAALLOO IINNTTEERRVVAALLOO I I INNNTTTEEERRRVVVAAALLLO I INNTTEERRVVAALLOO IINNTTEERRVVALLOO INTERVALO INTERVALOOOOOO MIGA SUA LOKA! QUE? IJO" O que tem pra comer? Pão Queijo tomate salsicha berinjela batata presunto alface hambúrguer cheddar maionese requeijão apresuntado carne peito de peru mortadela pão PIIIIIIIIIIIIIIIIIITRIMTRIMTRIMTRIMTRIMTRIM VOLTA PRA SALA. VEM LOGO. ANDA PARECE QUE ESTÁ MORRENDO. VAI MAIS ANIMO. JÁ ESTÁ TARDE PARA IR AO BANHEIRO. VAI LOGO PRA SALA. quero ir embora embora quero ir embora 
embora quero ir embora embora quero ir embora embora quero ir embora embora quero ir embora embora quero ir embora embora quero ir embora embora quero ir embora embora quero ir embora embora quero ir embora embora quero ir embora. QUE, PROVA? embora quero ir embora embora quero ir embora embora quero ir embora embora quero ir embora embora quero ir embora embora quero ir embora embora quero ir embora embora quero ir embora embora quero ir embora embora quero ficar embora quero ir embora quero ficar embora quero ir embora JÁ NÃO AGUENTO MAIS quero ficar embora quero ir embora quero ficar embora quero ir embora quero ficar embora quero ir embora quero ficar embora quero ir embora quero ficar embora quero ir embora quero ficar embora quero ir embora quero ficar embora quero ir embora quero ficar embora embora embora embora embora embora embora embora embora eu não vá fazer nada em casa, quero ir embora pois não aguento mais. Bom dia embora ir.

(Daniel, novembro de 2019)

\section{$¥ ¥$}

O conceito de signo aparece ao longo de toda a obra literária de Gilles Deleuze, apresentando-se de diferentes maneiras no decorrer do desenvolvimento das ideias por ele tratadas. Na perspectiva deste filósofo, o que faz do signo potente não é sua capacidade de nos fazer entender ou comunicar algo, mas é a sua capacidade de criação, pois está mais ligado ao verbo do que ao substantivo. Isto é, o signo não está ligado a uma procura pela transcendência para preencher de sentido um significado ausente, pois ele é um efeito corporal, ele diz respeito a percepções e sensações. Deleuze, em seu livro Proust e os signos (2003), faz suas primeiras considerações a respeito dos signos, baseado na obra de Marcel Proust.

Nessa obra, Deleuze associa a interpretação dos signos, em suas diferentes classificações, a um processo de aprendizado - dentro da perspectiva de que os signos nos forçam a pensar mais do que representam por si mesmos algo a ser conhecido. Nesse sentido é que Deleuze descreve o signo mais como uma ação de violência do que alguma forma que estaria no lugar de outra no processo de reconhecimento. Os signos, dessa maneira, estão mais para um ato do que para algum objeto ou representante (BELLO; ZORDAN; MARQUES, 2015, p. 2).

O signo é afecto, é um sentir diferentemente nos encontros, diz respeito à variação de nossa potência de existir, assim, o signo envolve a heterogeneidade e deixa de ser definido pelo imperialismo do significante. $\mathrm{O}$ encontro com signos transborda nossa percepção e 
carrega nossa experiência de sentimentos e disto decorre a necessidade do sentido e a urgência do pensar mais do que representar algo a ser conhecido.

Todo mundo pensa que pensa, mas será que pensa? As pessoas acham que pensam o tempo todo, mas não pensam, pois, pensar requer um arrombamento, requer sentir dor, mas pessoas não gostam de sentir dor. É natural as pessoas dizerem que pensam o tempo todo, mas não pensam. 0 pensamento não é natural. Pensar não é natural. As pessoas, simplesmente, repetem coisas velhas que estão na cabeça e na memória delas. Entender o que é um pensamento é fundamental para a questão do aprender. (SADER, 2018, p. 77).

No encontro com um signo o ato de pensar acontece, somos obrigados a pensar pela afetação que ele provoca, entretanto, "é porque todo mundo pensa naturalmente que se presume que todo mundo saiba implicitamente o que quer dizer pensar" (DELEUZE, 1998, p. 218). A teoria dos signos de Deleuze (2003) contribui para pensarmos a noção de aprendizagem de Matemática, é uma possibilidade para olhar de forma diferente o sujeito da educação e sua relação epistemológica com o mundo. Visto que, esta forma de compreender o signo possibilita questionar as práticas de ensino escolares tradicionais nas quais se concebe um sujeito que sempre estaria diante de algo que ele já conhece, algo preexistente a ele, que já existe independente dele (PLATÃO, 427?-347? a.C), um conhecimento abstrato e absoluto, construído sobre bases sólidas teoricamente aceitas pela Matemática.

\section{$¥ ¥$}

[...] Ao analisar brevemente alguns exercícios de função exponencial em uma aula dentro da "prática .ㅁ experimental", percebi que a maioria deles não exigiam muito dos alunos e como tal, não provocava crises neles, consequentemente, não eram de interesse, mas de cópia. Muitos esperavam a professora colocar "a resposta" na lousa para copiar. [...] "Professora, onde eu vou usar na minha vida logaritmo?" [...] Quando o professor é questionado sobre a utilidade do conhecimento que está ensinando, parece que se sente na responsabilidade de "ter que" responder para "convencer" o aluno do mot ivo para ele aprender tal assunto.

Mas o trabalho do professor não é convencer alguém a estudar algo, mas sim, através do seu envolvimento com aquele conteúdo, possibilitar que o aluno se interesse pelo poder de poder pensar ao contrário de "ter que". [...] A escola deveria ser o lugar das possibilidades, o lugar onde eu vou para poder pensar, para aprender a pensar, para me afetar com o mundo e este me afetar. 0 lugar onde a nova geração estuda conhecimentos e criar 
novos. Nova geração, conhecimento novo. [...] A escola deveria ser mais sobre envolvimento do que "fazer para". [...] A tentativa de iniciar um debate sobre a escola ensinar a responder várias perguntas factuais e não ensinar a pensar, não aconteceu. A ideia era boa, mas a mediação precisaria ser melhorada. Mas o que pode se perceber é a falta de costume de expor pensamentos, a falta de expor suas inquietações. Eles foram domesticados a esperarem a resposta do professor, porque o que ele diz está certo e contra o que ele diz não há argumentos. A escola deveria ser o lugar de questionar-se, questionar o outro, questionar o mundo, questionar a escola. [...] Dessa forma, não se dá a nova geração a menor chance de ser uma nova geração.

(Larissa, novembro de 2019)

\section{$¥ ¥$}

Quem aprende Matemática na escola, do modo em que a conhecemos hoje, lança mão de sistemas teóricos pré-estabelecidos, em que o objeto ou mundo a ser conhecido é tomado como idêntico a si mesmo, reafirmando a dualidade sujeito-objeto, isto é, reafirmando um aprender que parte do princípio da representação pelo qual a consciência distancia-se do mundo observado, e a existência de uma Matemática única, neutra e universal disciplinarmente organizada -. “Quem diz 'bom-dia Teodoro', quando Teeteto passa, quem diz 'são três horas', quando são três e meia, quem diz que $7+5=13$ ? O míope, o distraído, a criança na escola" (DELEUZE, 1988, p. 246).

Tais práticas prescritivas fazem parte das políticas de recognição presente nos currículos escolares de Matemática, escolas, máquinas do Estado, fabricando sujeitos reprodutores de saberes preexistentes a eles. Uma educação, um ensino de Matemática que treina e molda corpos. Práticas de ensino de Matemática que assujeitam corpos, que legitimam uma noção de aprendizagem como recognição, vinculada à ideia de um sujeito racional, centrado, unitário, um sujeito moderno (SILVA, 1995).

\section{$¥ ¥$}

\section{Corpos Presentes, Cidadãos Distantes}

O ponteiro do relógio se aproxima das sete,

Os corpos estão em movimento, Inquietos para serem confinados.

Um ritual que se repete.

o comandante do exército entra na sala, Como sinal de respeito, 
Todos se sentam, se anulam, a multidão se cala Enfileirados, imóveis, distraídos.

Seus corpos estão presentes,

Mas sua mente,

Muitas vezes prestam atenção vagamente. Muitos não gostam de estar ali, Mas pelos pais são obrigados, Com o protesto de que seu futuro Dependerá de tudo

Que na escola será ensinado. Será que para esses corpos chegarem a esse futuro, Os ensinamentos precisam ser tão chatos? O ensino precisa mudar, para que as pessoas parem de acreditar

Que a criança é uma folha em branco. Onde somente os aprendizados decorados e ditados pela escola

São os mais importantes para sua formação. Precisamos de corpos com pensamentos críticos Com sujeitos que pensam, opinam e agem Para que possamos formar uma sociedade com bons cidadãos.

(Meire Elen, abril de 2019)

\section{$¥ ¥$}

Assim, junto às atuais políticas neoliberais em Educação e, em Educação Matemática, tal como, os movimentos de luta e resistência consolidados nestas áreas nas últimas décadas, entendemos que é importante problematizar outras concepções sobre o aprender matemáticaS na escola junto a professores de Matemática em formação inicial, neste caso, a produção de escritas outras possibilitou desestabilizar algumas crenças, como que: aprender Matemática significa decorar fórmulas, repetir o modo como o(a) professor(a) resolve os exercícios, acreditar que seu conhecimento é importante porque "a Matemática está em tudo", porque é cobrada nas avaliações externas, para passar no vestibular ou porque influencia o bônus salarial de todos os professores.

Vale a pena notar que, trazemos a notação usada no Projeto matemáticaS, com "S" maiúscula no final, realizado pelo grupo de estudos Phala (Educação, Linguagem e Práticas Culturais) da Faculdade de Educação da Unicamp, em parceria com LABJOR-Unicamp nos aderindo ao projeto desconstrucionista de uma sistema universal e único de explicação, que se aproxima do que Clareto $(2013$, p. 7) denomina 'matemática menor' sendo aquela que "escapa à matemática régia e, junto a ela, em tensão com ela, vai se produzindo junto a livros didáticos, cadernos, exercícios, listas, deveres, provas, papéis, triângulos, definições". 


\section{$¥ ¥$}

Os alunos que estão do meu lado dizem não ter entendido o que é para fazer. Eles desabafam que não gostam desse professor, que, além de ele ser muito chato, ele não ensina bem. "Eu não aprendi nada de matemática esse ano. A matéria que costumava ser minha favorita, agora não gosto mais" , disse um deles. O professor chega na sala e escreve na lousa: "Fazer páginas 170 e 171, caderno do aluno" e fala: "Vocês têm que fazer isso que foi a única coisa que ficou faltando para fechar as notas”. Poucos são os alunos que prestam atenção.

Logo depois, uma aluna me pediu ajuda para resolver os exercícios da AAP. Ela não tinha vindo no dia e foi fazer hoje, porque o professor pediu. Expliquei todas as questões com ela. Na verdade, ela soube fazer tudo, só precisou de um empurrãozinho para entender as questões. Quando faltava só a última, ela desabafou: "Vim perguntar pra você, porque não entendo quando o José explica, ele não sabe explicar direito. A professora que eu tinha ano passado explicava tudinho, eu entendia tudo. Você me explicou agora e entendi tudo. Mas com ele eu não consigo entender nada”. Ela também mencionou o fato de que parece que ele não prepara nada pra dar aula. A aula acabou justo quando terminamos de fazer o último exercício.

[...] me incomodei extremamente com o professor que o José era. Muitas dúvidas vieram na minha cabeça. Será que ele prepara as aulas dele? Se ele prepara, qual é o raciocínio dele ao pensar em uma aula nova? Será que ele conhece diversas metodologias de ensino? Será que ele sabe a diferença da aula tradicional e das outras aulas? Será que ele se preocupa em dar uma aula em que o aluno realmente aprenda a matéria? Ou será que ele só está preocupado com as notas das avaliações feitas pela Secretaria de Ensino? Será que ele gosta de dar aula? Será que ele realmente queria ser professor? Será que ele não seria melhor em outra profissão?

(Ana Laura, novembro de 2019) 


\section{$¥ ¥$}

$\mathrm{Na}$ heterogeneidade das afetações produzidas nos encontros com o signo, pensar em matemáticaS torna-se um movimento desconstrutivo que questiona, tanto o regime disciplinar da escola, quanto o desejo de manter um sistema explicativo universal e totalizante, vinculado à palavra Matemática com " $\mathrm{M}$ " maiúsculo, compreendida enquanto disciplina acadêmica. Toda vez que, pensar como afetação significa decifrar os signos que irrompem na vida dos sujeitos diante de uma violência produzida por um problema. São os signos que tocam o sujeito e não os objetos propriamente ditos,

o signo, em certos encontros, é aquilo que não dado no dado percebido ou no sentimento sentido, intensifica minha sensibilidade (a essa intensificação do sensível é que se dá o nome de sensação), a tal ponto que, escapando ao poder recognitivo da consciência perceptiva ou sentimental, força-me a pensar para além da representação (novos conceitos), a perceber de outro modo (novos perceptos), a sentir de outro modo (novos afectos), a aprender por decifração, isto é, por experimentação do desconhecido (ORLANDI apud NASCIMENTO, 2012, p. 130).

Esta transgressão, no uso da palavra do singular, para o plural, está relacionada com a concepção de prática social como lugar onde algo se passa, onde relações acontecem. Possibilidade de uma relação da prática, signo e pensamento que não é redutível à aplicação de saberes ou à rememoração de vivências dadas, uma vez que ela se constitui como um aprendizado voltado para o problemático, um aprender como um "encontro com signos".

\section{$¥ ¥$}

Perguntas "como?" ou "para que eu vou usar isso?"
apontam para a matemática ensinada na escola: uma
matemática que faz decorar. Os alunos foram acostumados a
receberem do professor o como se faz, a receita do
exercício. As vezes, antes mesmo de lerem o enunciado e
tentarem começar a pensar, já surge a pergunta quase que
automática: "Professor, como é pra fazer?".
[...J A pergunta "como é pra fazer?" pode indicar que o
aluno pergunta ao professor por que é ele quem sabe o que
é correto ou não, e é a resposta dele que é certa. Fomos
ensinados dessa forma e, geralmente, quando vamos por um
caminho que o "professor não fez", apagamos nossa
resposta e copiamos a do professor. Foram muitas aulas
sobre logaritmo e suas propriedades. Em poucas delas, os
alunos se afetavam em pensar. A professora indicava
exercícios do caderno do aluno para que os alunos
fizessem. Alguns se "comprometiam" em fazer, outros em


copiar do colega e outros, bom, estes se afetavam com outras coisas que não eram os exercícios.

Em pouco tempo a sala “dispersava”, e a professora, como que em uma atitude para pará-los começava a escrever as respostas na lousa. Quando eu passava pelas carteiras a fim de ajudar os alunos, tentava não deixar a ansiedade de dar a resposta me atrapalhar e devolvia as perguntas deles com outras perguntas. Uma que quase se tornou um jargão foi: "O que é logaritmo?" O meu objetivo era sempre provocá-los a fim de que pensassem. Isso porque a gente acha que sabe pensar. Homo sapiens sapiens. [...] A matemática ensinada na escola me faz pensar? "Para esse exercício temos cincos passos $\cdots$ são bem simples $\cdots$. É só seguir o passo a passo." Passo a passo. Pode ser até colocado na galeria de jargões da matemática escolar. Essa matemática-receita se torna interesse para os alunos? Essa matemática nos leva a estudar, pensar e praticar? [...] A matemática transmitida na escola move os alunos a pensarem? Ela os violenta levando-os a uma crise?

(Larissa, novembro de 2019)

\section{$¥ ¥$}

Encontros com signos que sempre se dão na participação de práticas de uma coletividade em que fazemos das relações a experiência com o signo. Encontros de corpos que vibram com os signos que chegam na impossibilidade do possível nos encontros, como acontecimentos e, nessa vibração, nossa capacidade de sentir e pensar o mundo de modos outros nos transforma. Aprendemos com o corpo todo, como motor daquilo que estamos nos tornando, sempre nos tornando com as matemáticaS que acontecem. Aprender matemáticaS no encontro com signos que, no lugar da presunção do pensamento que se debruça sobre si mesmo para si mesmo, - um pensamento autocentrado -, coloca-se sob o acontecimento no encontro entre corpos que vibram e se impressionam e se impactam e se afetam por seus signos.

Apontamos para uma visão do aprender matemáticaS como devir, como acontecimento e, neste sentido, Kastrup (2005) afirma que o aprender acontece no encontro entre professores e alunos e corpos humanos e corpos não humanos, encontro de forças e potências e experiências não recognitivas.

Nos aproximamos de uma compreensão do aprender (matemáticaS) enquanto devir de afectos e perceptos. Os afectos como efeitos de potência sobre a vida, da experiência, e os perceptos, compreendidos como novas maneiras de ver ou perceber. Isto porque, signos nos remetem aos modos de vida em que estamos inseridos, nos quais qualquer tipo de tentativa para capturar sua essência, para produzir uma significação última ou representação, se frustra, pois, pensar nos modos de vida é pensar nas práticas sociais enquanto produtoras e 
mobilizadoras de saber.

\section{$¥ ¥$}

Os alunos vivem na escola pensando o tempo todo no horário que eles irão sair ( "Olha professor, desenhei meu objeto preferido: A porta de saída da escola”), já que, enquanto eles ali estão, ocorre uma domesticação, ignora-se seus conhecimentos e, por mais que sejam boas as intenções dos participantes da escola, o aluno interpreta que aquele não é seu espaço de ser, é seu espaço de responder ( "Precisamos explicar para os alunos a importância da AAP e pedir um pouco de responsabilidade deles”), assim o espaço de ensino acaba se transformado em um aparelho disciplinar.

Porém, quando falamos sobre respeito na escola sempre pensamos apenas nos alunos respeitando os professores ( "Mandei pra fora porque não me respeitou") ( "Por que tá olhando aqui pra dentro? Me respeita!"), porém, quase nunca pensamos na recíproca.

A visão hierárquica assumida pelo sistema escolar admite a impossibilidade da falta de respeito do professor e da administração, pelos alunos, tornando estes participantes da escola "acima da lei", neste caso ("Que sacanagem isso, é meu dinheiro que estão jogando fora. Ficam dando material pra vagabundo"), de fato nem os alunos esperam ser respeitados ( "Aqui ninguém é obrigado a gostar de ninguém, ele não gosta de mim e eu não gosto dele”).

(João Gabriel, novembro de 2019)

\section{$¥ ¥$}

Assim, esta escrita busca contribuir para a discussão e problematização dessas ideias já contidas em diversas referências na área da Educação (Matemática) apontando para a valorização de outros modos de aprender e ensinar, possibilidades de práticas de ensino outras, resistências ao currículo e aos discursos que podem ser deterministas e que entendemos que funcionam a favor da produção de corpos dóceis (CLARETO, 2012; GALLO, 2012; GONDIM; MIARKA, 2017).

\section{$¥ ¥$}




\section{Escrita de Março}

Hoje

40 também pode ser 40.000

40 pode ser 40,000?

eis que a professora me encurrala

ela me rala

na frente de todos

não sei o que falar

de todos os métodos

eu não podia ela calar

falei que estava certa

mesmo duvidando da sua agência

da sua potência

dentro de sala de aula

que se vai dia após dia

"mas esse aluno é mesmo uma mula"

"mas ela não tem mesmo nostalgia"

Tenho certeza de que ambos queriam dizer isso a mim nesta hora mesmo que o silêncio eterno os calasse

coitada dessa classe

Vontade é de jogar uma granada somente de informação, claro! para não acontecer que nem em Suzano, algo raro que chegou e pah, paro

é só fazer o reparo mais nada.......

(Daniel, março de 2019)

\section{$¥ ¥$}

Neste sentido, apontamos para a necessidade de práticas de resistência, microrevoluções, diante das políticas de recognição presentes nos programas escolares, entendendo que, estas podem se manifestar ao nos incomodar, por exemplo, com as práticas instituídas nos currículos de Matemática, problematizando-as no sentido que se discute neste texto. Uma vez que, entendemos que contribuem de forma direta ou indireta com a produção de corpos dóceis. Daí a necessidade de tensionar o modelo representacional do conhecimento 
da tradição filosófica ocidental, que sustenta a ideia de um sujeito que possui a priori, a capacidade de conhecer e de representar as coisas, pois, sabemos que, "Existem alguns indícios de que a Matemática da escola é factual, de que os signos que os alunos aprendem não são os da Matemática, e sim os signos que estão por trás da lousa, que se aprende o tempo todo numa aula de Matemática que não é a Matemática" (SADER, 2018, p.81, grifos do autor).

Então, que Matemática ${ }^{6}$ ? matemáticaS? Matemática com lousa? Lousa com Matemática? Cálculos na lousa? Fórmulas na lousa? Exercícios na lousa? Teorema na lousa? Como isolar o " $\mathrm{x}$ " na equação que está por trás da lousa? Professor de Matemática sem lousa? Professor, eu errei? Professora, eu pensei certo? Eu posso resolver o exercício de outro jeito? Professora, é assim que resolve esse problema? Cadê a lousa no confinamento social ${ }^{7}$ ? Aula virtual de Matemática com lousa? Aula de Matemática com livro? Com texto? Rasguem os livros? Critiquem os textos? Começar o livro didático de Matemática pelo capítulo 3? Que Matemática é essa do currículo escolar? Currículo ocidental? Ideias matemáticaS do povo Gunadule $^{8}$ ? Sona ${ }^{9}$ na aula de Matemática? Conhecimentos africanos e afrobrasileiros na aula de Matemática? Desenho na aula de Matemática? Qual escola é essa? Obra de arte e aula de Matemática? Perguntas que mobilizam olhares outros e escritas outras que acontecem no espaço da escola, da universidade, questionamentos que permitem um dançar com a vida que ali acontece, no seu próprio ritmo.

Nesse dançar com a vida, entendemos que, escritas outras também vão produzindo práticas de resistência, micro-revoluções, formação de professores de Matemática outras, que abrem margem para desnaturalizar o 'natural', desestabilizar as políticas recognitivas que nos afastam das possibilidades de um aprender com signos, um aprender pelos afectos, em que se manifesta um pensar que nasce e renasce para liberar a afirmação da diferença.

\section{$¥ ¥$}

\footnotetext{
${ }^{6}$ Clareto (2013).

${ }^{7}$ Vemos a importância de abrir debates maiores sobre ensino e aprendizagem de Matemática por meio do Ensino Remoto na perspectiva por nós aqui discutida. Pensar sobre isto se faz necessário, diante das demandas sociais e educacionais que emergiram a partir do confinamento social produzido mundialmente em 2020 por causa da pandemia "Covid-19", pois como apontado em Tamayo e Silva (2020, p. 31) "[...] a escola, entendida como instituição do aparelho do Estado, já antes da pandemia enfrentava diversas problemáticas considerando a desigualdade social, os fatores históricos, políticos e econômicos do Brasil, que tornaram-se ainda mais graves com a chegada do "Covid-19"; além do mais, os sujeitos participantes da escola viram-se obrigados a enfrentar a "crise da educação escolar"”.

8 Tamayo (2017).

9 Tamayo, Tuchapesk (2018).
} 


\section{"O antes e o Depois"}

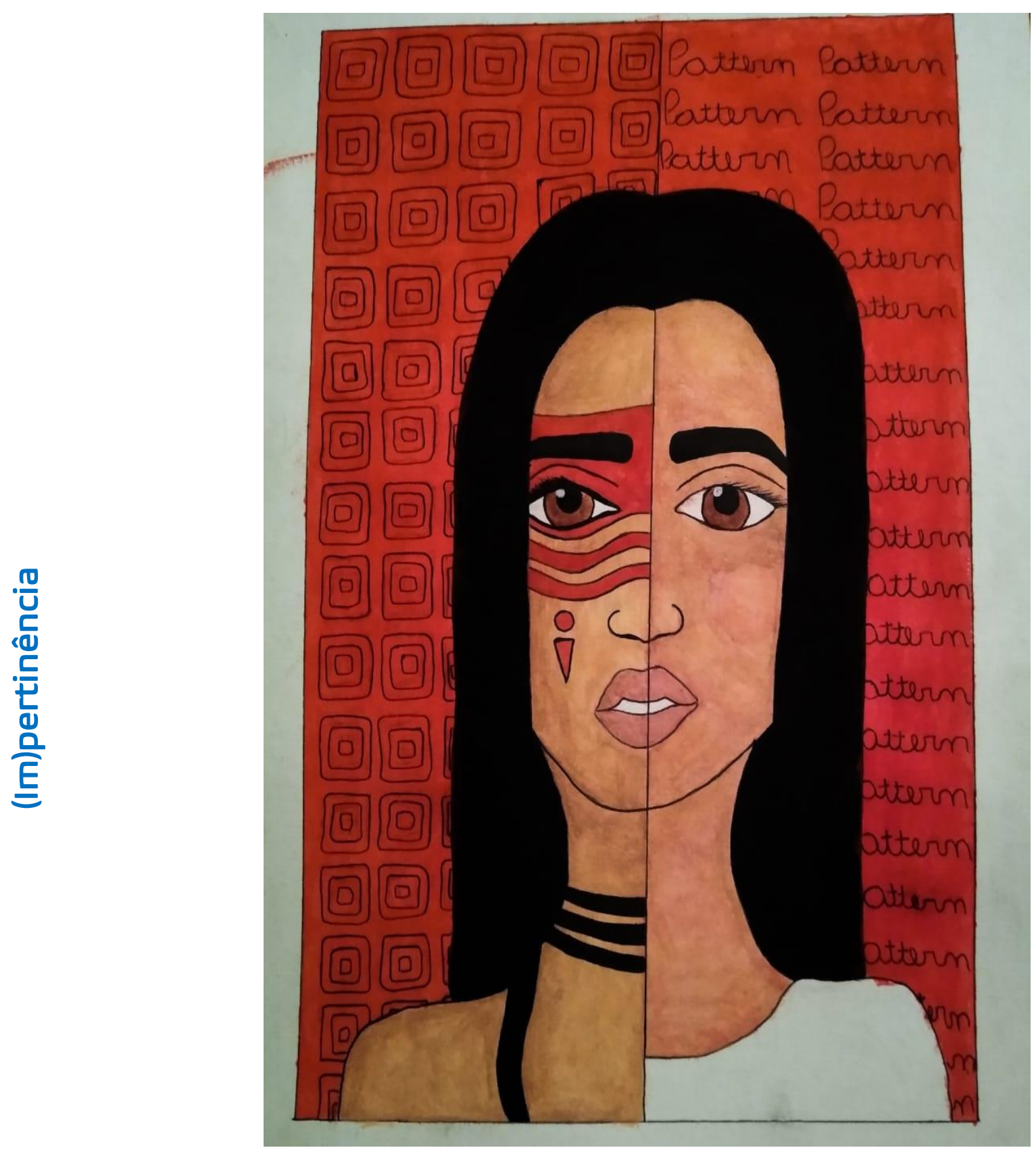

(Luan, março de 2019)

\section{Referências}

BELLO, Samuel E. L.; ZORDAN, Paola; MARQUES, Diego. Signos e interpretação: entre aprendizagens e criações. Cadernos da Educação, n.52, 2015. Disponível em:

https://periodicos.ufpel.edu.br/ojs2/index.php/caduc/article/view/7315.

CLARETO, Sonia M. A sala de aula e a constituição de um currículo-invenção. Currículo sem Fronteiras, v.12, n.3, p. 306-321, Set/Dez 2012. Disponível em:

http://www.curriculosemfronteiras.org/vol12iss3articles/clareto-nascimento.pdf. 
CLARETO, Sonia M. Matemática como acontecimento na sala de aula. Anais da 36a Reunião Nacional da ANPEd -29 de setembro a 02 de outubro de 2013, Goiânia-GO.

COSTA B., Cristiano; ROSA P., Marcele. Uma escrita sobre nada. 2017. Disponível em: https://www.yumpu.com/pt/document/read/12590950/escrita-sobre-nada-ufsm.

DELEUZE, Gilles. Diferença e repetição. Trad. Luiz Orlandi e Roberto Machado. Rio de Janeiro: Graal, 1988.

DELEUZE, Gilles. Proust e os signos. Trad. Antônio Carlos Piquet e Roberto Machado. 2.ed. Rio de Janeiro: Forense Universitária, 2003.

DELEUZE, Gilles. A ilha deserta e outros textos. São Paulo: lluminuras, 2006.

DELEUZE, Gilles; PARNET, Claire. Diálogos: Gilles Deleuze e Claire Parnet. Trad. Eloisa A. Ribeiro, São Paulo: Escuta, 1998.

GALLO, Silvio. As múltiplas dimensões do aprender. Anais do Congresso de Educação Básica: aprendizagem e Currículo. 2012. Disponível em: http://www.pmf.sc.gov.br/arquivos/arquivos/pdf/13_02_2012_10.54.50.a0ac3b8a140676ef8ae0dbf 32e662762.pdf.

GONDIM, Diego; MIARKA, Roger. A constituição de um plano de intensidades: aprender e matemática e diferença e escrita-avalanche e... Perspectivas em Educação Matemática, v. 10, n. 22, p. 115-131, 2017. Disponível em: http://seer.ufms.br/index.php/pedmat/article/view/3359.

NASCIMENTO, Roberto D. S. Teoria dos signos no pensamento de Gilles Deleuze. 2012, no de folhas 216. Tese (Doutorado em). - Instituto de Filosofia e Ciências Humanas. Universidade Estadual de Campinas. 2012.

PLATÃO (427?-347? a.C). Diálogos VII (suspeitos e apócrifos): Alcibíades, Clitofon, Segundo Alcibíades, Hiparco, Amantes rivais, Teages, Minos, Definições, Da justiça, Da virtude, Demódoco, Sísifo, Hálcion, Erixias, Axíoco/ Platão. Tradução, textos complementares e notas: Edson Bini. Edipro. Bauru, SP, 2011.

SADER, Simone Aparecida da Costa. Eu, ex-aluna, observei, mapeei e experimentei movimentos da Educação Matemática na minha escola de Ensino Básico. 2018. 158f. Dissertação (Mestrado em Educação Matemática) - Instituto de Geociências e Ciências Exatas, Universidade Estadual Paulista, Rio Claro, 2018.

SILVA, Tomaz Tadeu. O projeto educacional moderno: identidade terminal? In: VEIGA-NETO, A. (org.). Crítica pós-estruturalista e educação. Porto Alegre: Sulina, 1995. p. 245-260.

TAMAYO, Carolina. Vení, Vamos hamacar el mundo, hasta que te asustes: uma terapia do desejo de escolarização moderna. 2017. Tese (Doutorado em Educação) - Universidade Estadual de Campinas. Disponível em http://repositorio.unicamp.br/jspui/handle/REPOSIP/325354.

TAMAYO, Carolina; TUCHAPESK, Michela da Silva. E se nós tivéssemos escolas Mukanda que contassem diversas histórias africanas para todo o mundo? Educação Matemática em Revista, n. 60, p,263-28, dez. 2018. Disponível em: http://www.sbem.com.br/revista/index.php/emr/article/view/1252\&gt. 
TAMAYO, Carolina; TUCHAPESK, Michela da Silva. Desafios e possibilidades para a Educação (Matemática) em tempos de "Covid-19" numa escola em crise. Revista Latinoamericana de Etnomatemática, 13(1), 29-48. 2020. Disponível em:

https://www.revista.etnomatematica.org/index.php/RevLatEm/article/view/579/497

KASTRUP, Virginia. Políticas cognitivas na formação do professor e o problema do devir-mestre. Educação e Sociedade, Campinas, v.26, n.93, p. 1273-1288, 2005. Disponível em:

http://www.scielo.br/scielo.php?pid=S0101-73302005000400010\&script=sc iabstract\&tlng=pt.

UBERTI, Luciane; BELLO, Samuel E. L. A docência-pesquisa em movimento no PIBID. In: UBERTI, Luciane; BELLO, Samuel E. L (Orgs.). Iniciação à docência: articulações entre ensino e pesquisa. São Leopoldo: OIKOS, 2013. pp.17-32.

\section{Agradecimentos}

Agradecemos a cada um dos alunos de graduação das disciplinas de estágio supervisionado da Licenciatura em Matemática da Faculdade SESI-SP de Educação de São Paulo e do curso de Licenciatura em Ciências Exatas, IFSC, USP- São Carlos por terem nos permitido de forma consentida trazer suas escritas para este artigo como parte dos nossos projetos de pesquisa sobre formação de professores de matemáticas através das lentes da Filosofia da Diferença. 